Journal of Contemporary Educational Research

Research Article

\title{
Exploring the Practice of Cultivating Design Thinking Skills in Visual Communication Major
}

Li Bai*

School of visual communication design, Lu Xun Academy of Fine Arts, Shenyang 110004, Liaoning Province, China

Abstract: The development of diversified industries has promoted the emergence of diversified majors, and visual communication is a new type of profession, and the course is also a new type of course, which requires students to have better design thinking, and how to improve the design thinking of visual communication majors through daily learning. Based on this, this paper proposes a definition of visual communication and the relevance of design thinking. It proposes a strategy to enhance the design thinking ability of visual communication majors.

Keywords: Visual communication; Professional design; Thinking ability; Training

Publication date: August, 2020

Publication online: 31 August, 2020

*Corresponding author: Li Bai, syb903@163.com

\section{Visual Communication Overview}

\subsection{Introduction to the Department of Visual Communication}

At present, visual communication majors in the major art colleges and universities have been opened, the main goal of the course is to cultivate artistic qualities and essential functions of the technical personnel, with design capabilities and the corresponding application of performance, course employment in various types of enterprises and companies that include the major ${ }^{[1]}$.

Along with the rise of visual communication, there are about a dozen local colleges. Universities have art, and design majors, especially the current graphic art design, environmental art design, video art design, animation art design, website art design and other employment demand increases, some training college students also opened art and design majors, to attract students to apply.

\subsection{The correlation between visual communication and design thinking}

1.2.1 Visual communication language needs constant innovation

Visual communication is a work of art that uses the elements of many forms as its visual language. The artistic expression of the artwork is the symbols of visual communication. Visual symbols are not used to express abstract concepts but to express perceptual image concepts. Regardless of the development of the language of visual communication, it is necessary to create an entirely new visual image, i.e. visual communication symbols of an image, symbols of different content and symbols of various forms ${ }^{[2]}$. Especially in visual communication, without creativity and novelty, visual communication symbols will not be attractive and will not stand out in complex visual messages. Therefore, it is essential to focus on innovation in visual communication materials, visual communication shapes, visual communication colors, visual communication text, and visible communication decorations.

\subsubsection{Visual communication design concepts need constant innovation}

Visual communication is the preferred method of accomplishing information more accurately, and visual images can make a particular understanding more intuitive to an audience. Visual communication increases the quick effectiveness, timeliness, and flexibility of information to make an impact and attract unexpected attention. Visual communication makes the creativity 
of the communicator more vivid and imaginative. It makes the state and process of information transmission more artistic. In the universality of visual aesthetics, different types of visible communication use elements of various forms of visual language to regularly form visual communication artworks. The artistic expression of a work of art is symbolic of visual communication.

\subsubsection{The process of artistic development requires a new approach}

Visual communication is both a means of communication and a cultural form, and art is an essential feature of design thinking. Development requires constant innovation. Visual communication is essentially innovation, and artistic innovation is the life of art and design. Therefore, good art designers always emphasize innovation and originality ${ }^{[3]}$. The design of visual communication in the 21 st century is international, localized, humanized and original. It shows the characteristics of inclusiveness, vitality, three-dimensional gender, time and space, interactivity, intersectionality and so on.

\section{The Importance of Cultivating Design Thinking Skills in Visual Communication Major}

\subsection{Social, environmental requirements}

The complexity of the social environment demands that design thinking skills must be developed in visual communication education for college students. Visual communication itself is the transmission and design of optical signals and information. How to accurately express enough information and effectively convey visual information is the key to visual communication. At present, the level of development of social science and technology is continually improving, and the social order is rapidly changing, people's ideas and concepts are constantly changing, people's emotions are constantly changing, people's thoughts are constantly changing, visual and visual influence communication on people. Innovation in the curriculum ensures that the content of visual communication design is distinguished from complex information so that people can understand the issues clearly and distinctly ${ }^{[4]}$. In optical communication education, the innovative design must be based on essential content to convey and receive useful information.

\subsection{Market development needs of creative industries}

To develop a market for creative industries, there is a need to develop design thinking skills for visual communication students. Visual communication design works can not only modify existing designs but also sculpt them together, without initiative, these works will not be removed or recognized from the market, and there is no market space. Currently, the market for creative industries demands not only their level of expertise, but more importantly, how intense their creativity is, and how innovative they are. Therefore, it is a necessity of the market situation to develop the design thinking ability of visual communication students.

\section{Current Situation of Cultivating Design Thinking Skills in Visual Communication}

\subsection{Lack of awareness of innovative design}

Innovative design consciousness is one of the foundations of visual communication majors, only a good sense of creativity can show better visual communication works, through the questioning of school teachers, the current data reflected in the innovative consciousness and spirit among students is shown in Figure 1. This indicates that there is a severe lack of creating awareness among students, which needs to be further improved ${ }^{[5]}$.

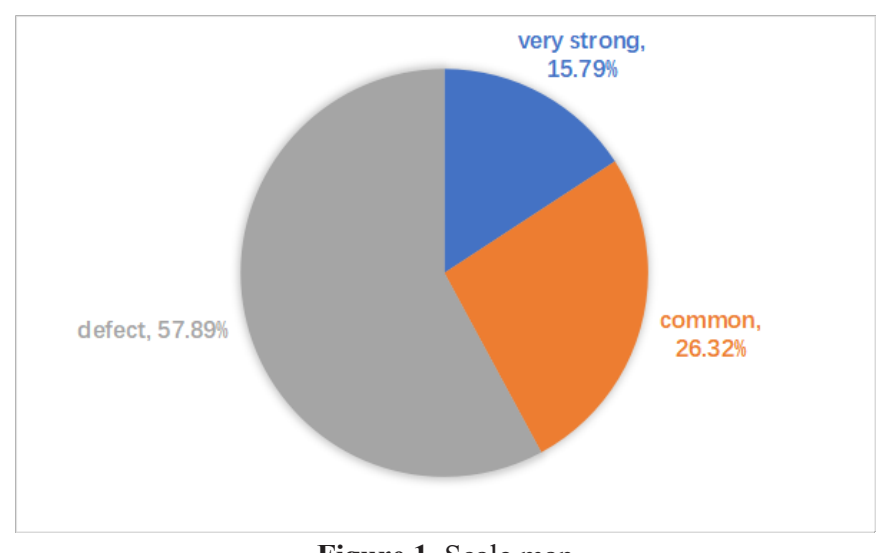

Figure 1. Scale map

Modern design and art in China stem from traditional Chinese values and traditional Chinese painting and drawing concepts, which have a positive or limited influence on the development of design thinking skills of college students. In personal interviews, more than $20 \%$ of junior visual communication education teachers reported that traditional Chinese values had a positive impact on the development of design thinking skills of visual communication students, while more than $30 \%$ of junior visual communication education teachers 
were Traditional Chinese reported that the values were explicitly designed for optical communication students. The impact of thinking skills training was evenly distributed ${ }^{[6]}$. Nearly $50 \%$ of elementary teachers in visual communication education reflect traditional Chinese values, but there are limitations in developing design thinking skills for visible communication college students. More than $30 \%$ of elementary teachers in visual communication education reflected traditional Chinese art Design Visual communication had a positive impact on the development of design thinking skills of college students. Almost $20 \%$ of elementary teachers in visual communication education were traditional Chinese art. The effect of design on the development of visual thinking skills was reported to be average for college students' design thinking skills. More than 50\% of the primary school teachers of visual communication education in China believe that traditional art and design have limitations in developing the design thinking skills of visual thinking college students.

\subsection{Weak systematization of knowledge}

In the early 1980s, Chinese art and design absorbed Western teaching methods, especially the introduction of the Bauhaus philosophy of education. Still, the application of the Bauhaus philosophy of education in Chinese art education did not fully reflect its essence, but instead focused on art education itself, according to national conditions. Not enough attention should be paid to the science and logic of art education ${ }^{[7]}$. Since visual communication has an artistic character, Table 1 shows whether visual communication education focuses on the culture of creative knowledge, the development of artistic skills or the results of systematic scientific

of unique paradigms, to break out of the confines of traditional experience, to create creativity openly and flexibly and to develop a sense of independence. The strengths and weaknesses of visual communication education, its content, pedagogy and assessment methods can influence students' design thinking. In personal interviews about visual communication education content design, $31.58 \%$ of visual communication education teachers currently believe that visual communication education content design is systematic. In comparison, $68.42 \%$ of visual communication education teachers now believe that visual communication education content design is monotonous ${ }^{[8]}$. In the personal interviews about how communication education is conducted, $26.32 \%$ of visual communication education teachers believe that current methods of visual communication education are inclusive.

In comparison, $73.68 \%$ of visual communication education teachers believe that current methods of visual communication education are monotonous. In the personal interviews on the evaluation methods of audiovisual teaching, $78.95 \%$ of the audiovisual education teachers believed that the current methods of evaluation of audiovisual education are strict. In comparison, $21.05 \%$ of the audiovisual education teachers thought that the current plans for the assessment of audiovisual knowledge are flexible.

\section{Cultivating Design Thinking Skills in Visual Communication}

\subsection{Development of divergent thinking}

Table 1. Visual Communication Education Priorities

\begin{tabular}{ccc}
\hline Development focus & Options & Percentage \\
\hline \multirow{3}{*}{ Artistic knowledge, aesthetic ability } & Attach great importance to & $68.42 \%$ \\
& General emphasis & $21.05 \%$ \\
& Indifference & $10.5 \%$ \\
\multirow{2}{*}{ Systemic knowledge, innovation } & Attach great importance to & $31.58 \%$ \\
& General emphasis & $26.32 \%$ \\
\hline
\end{tabular}

knowledge and innovation of works.

As can be seen from the above table, art teachers focus more on the development of artistic knowledge and aesthetic skills, with relatively little emphasis on innovation and systematization of works.

\subsection{Less effective teaching}

The key to shaping design thinking is to break out
Students are encouraged to develop their thinking and to use a variety of thinking in their visual communication education. The optical communication design process allows students to use a variety of ways of thinking to design ideas based on their own identity and career. These ideas always emerge and, combined with the evaluation criteria of the visual communication design process itself; students can use a variety of approaches 
to design unique ideas and select the most accurate design plan. In practical training, brainstorming can be used to train design. Brainstorming is a group of people who use their brains to think creatively. It is possible to solve problems and come up with many ideas in a short period. Implementation methods usually include group thinking and individual thinking. Group discussions take the form of group thinking and a general meeting of shareholders, where similarly a group of people stimulate creative problem solving by presenting all the ideas presented by the chairman and two secretaries to the meeting participants. Usually, what is called brainstorming is a form of collective thinking. In visual communication training, the group can think outside the box. Each student comes up with one or more ideas based on the situation ${ }^{[8]}$. The president and two secretaries then organize and discuss all the ideas the group has come up with. We can use our brains to stimulate creativity and produce outstanding visual communication work.

For unquestionable, free and scalable brainstorming, as many people as possible can be placed in the form of an actual group of teachers (e.g., principal, class president and study committee).

\subsection{Development of associative thinking}

Association is the process of thinking from one thing to another based on specific correlations. Associations can be considered from a point on a plane to four directions, or they can be projected from a point layer by layer to a straight line based on the stream of consciousness. The interaction exists in the process of communication. For example, in the visual communication of a realistic idea, the designer can find symbols to describe the view through the association of form and shape, and the viewer can understand the meaning of the symbols through the association of way and shape.

(1) Internal "connections" may be formed between apparently unrelated things because of external or internal similarities.

(2) Similar shapes or similar external characteristics may lead to correlations, e.g. a bar code used in life can be connected to a fence, and an animal can open and escape the wall. Placing barcodes horizontally is like jumping high in a sport.

(3) How various concepts can be related to abstract concepts with the help of symbolic meanings, e.g. an advertisement for a particular laundry detergent can be designed for laundry detergent alone.

(4) Can correlate associations formed by temporal and logical connections between objects, e.g. the connection button on a wheel and clothes.
(5) Individuals can be replaced with groups, partially replacing all associations in a graphic, compressing forms by alternative associations, and reproducing the most expressive and formal parts to form an image of aesthetic value.

\subsection{Inspirational thinking}

Inspiration comes from the imagination. Based on perceptual material, the image of memory is processed and transformed to create a new image. In modern graphic creation, inspiration is the processing of metal obtained by association. It is based on the memory image, with the help of experience, according to people's feelings and intentions, to rework and shape the new image, to establish an original painting ${ }^{[9]}$. In the teaching of visual communication in college students, existing materials are reorganized and constructed to rebuild the corresponding new model based on the inspiration of human language or graphics. For example, in the visual communication of graphic creativity, we can take inspirational thinking to create graphics.

(1) Reverse graphic design. If the relationship between the picture and the floor is used to create the graphic, the image may be considered positive, or if the complementary shapes are negative, the positive and negative ways may be borrowed from each other or in the opposite direction.

(2) Symbiotic graphic design. Two or more shapes are fully shared in the same space, sharing or interdependently sharing the same side to create necessary forms. Decorative composition, i.e., different ways can be divided, all shapes in different directions and more than one shape can coexist in social space, i.e., regional sharing of forms.

(3) Punning graphic design. Graphics can be interpreted in two different physical forms at the same time, creating meaning and conveying a clear visual message through the connection between the two tangible ways. A pun implies that the graphic contains a double interpretation, one with a superficial meaning and the other with implied meaning. The implied purpose of the album design is usually the primary meaning of the graphic, where words have different meanings.

\subsection{Backwards thinking}

Historically, this is a type of thinking that is the opposite of traditional thinking and mystical thought that is novel and rebellious. Retrograde thinking is divided into directional retrograde thinking, attribute regressive thinking, principle retrograde, paradox, causal retrograde and psychological retrograde. The 
current composition of college students is diverse and complex, with not only substantial age differences, but also differences in learning levels and motivations for expressing diversity ${ }^{[10]}$. College students come from different fields, have different social experiences, different professional backgrounds, different knowledge systems and different lifestyles, and therefore need to focus on the distinct characteristics of college students and use different approaches in their visual communication education practices. Cultivate different ideas.

(1) Make connections in opposite directions from the starting point of conception and find relevance. Colds and fevers, fast and slow, high and short, war and peace; breaking the top of a visual image, thinking in directions opposite to the existing visual direction of the object or the course of the object's development, and changing the unique features and characteristics of the purpose. Backward Thinking Functions. Undergraduate students are less motivated and less active, and existing teaching methods can lead to fatigue and lack of motivationmeaningless problems with teaching effectiveness.

(2) In this investigation, the principles of appropriate and proper traditional Chinese design, the value of living in harmony with nature, and spiritual pursuits have had some impact on design innovation in visual communication rather than on the enthusiasm of undergraduates for innovative design concepts. In particular, the secure transmission of traditional experiences and skills has limited influence on and hindered the development of creative design thinking in visual communication. For this reason, classic art, about rationality and realism, breaks with custom and common sense, and logic and order transcend objective realities and temporal limitations.

\section{Summary}

In summary, the development of dispersed thinking based on various student characteristics, or the development of relevant ideas based on the passive learning characteristics of college students, the development of inspirational thought based on the behavioural characteristics of college students, and the consolidation of traditional independent design thinking skills based on various aspects of college students this is not training. Still, the development of different innovative design thinking styles as a complete whole, each thinking style is mutual related and exist independently of each other. This systematic training of design thinking skills can actually systematize knowledge, effectively solve the problem of insufficient knowledge of college students, improve students' sense of innovation, and effectively improve teaching effectiveness.

\section{References}

[1] Xu Y. Studio-based Teaching in Visual Communication Design from the Perspective of Industry-Education Integration--Review of the Educational Research and Teaching Practice of Visual Communication Design[J]. China Education Journal, 2020(07): 142.

[2] Zhang SC. Exploration of the creator-type curriculum of visual communication design majors under the background of big data[J]. Contemporary Education Practice and Teaching Research,2020(08): 45-46.

[3] Zhang GC, Liu JR. Research on Innovation and Entrepreneurship Education in Visual Communication Design[J]. Reference for Middle School Political Science Teaching, 2020(12): 103.

[4] Liu J. Research on Creative and Incentive-Oriented Training Mode of Innovative Design Talents: Taking Visual Communication Design Major as an Example[J]. Innovation and Entrepreneurship Theory Research and Practice, 2020, 3(07): 144146.

[5] Cui XJ. Cultivation of students' creative thinking ability in the teaching of senior visual communication design majors[J]. Educational Observation, 2019, 8(40): 118-119.

[6] Wei CX. The cultivation of the creative ability of visual communication design students in colleges and universities[J]. Art Education, 2015(12): 67.

[7] Guo QY. The cultivation of the creative thinking ability of visual communication design majors[J]. Drama House, 2014(10): 333. 